\title{
Ovarian Epithelial Tumor
}

National Cancer Institute

\section{Source}

National Cancer Institute. Ovarian Epithelial Tumor. NCI Thesaurus. Code C4381.

A benign, borderline, or malignant tumor that originates from the surface epithelium of the ovary. It is composed of epithelial cells and stroma. Representative examples of benign tumors include serous cystadenoma, mucinous cystadenoma, and benign Brenner tumor. Representative examples of borderline tumors include serous surface papillary tumor, mucinous adenofibroma, and borderline Brenner tumor. Representative examples of malignant tumors include serous adenocarcinoma, mucinous adenocarcinoma, endometrioid adenocarcinoma, and malignant Brenner tumor. 